\title{
Injection Needle Reuse
}

National Cancer Institute

\section{Source}

National Cancer Institute. Injection Needle Reuse. NCI Thesaurus. Code C156549.

The use of injection needles that have been previously used. 